\title{
OPPORTUNITY COST APPROACH EVALUATION OF URBAN TRAFFIC CONGESTION COSTS AT ORLU-ROAD BY WAREHOUSE INTERSECTION IN OWERRI METROPOLIS
}

\author{
DURUAKU CHIGOZIRIM C. \\ Department of Transport Management Technology, Federal University of Technology, \\ Owerri, Nigeria \\ Corresponding Author's Email: claribelduruaku@gmail.com
}

\begin{abstract}
This study estimated the economic cost of urban traffic congestion trip-time delay and extra vehicle operating cost at the Orlu-road by warehouse intersection in Owerri Metropolis, Imo state, Nigeria. Adopting the survey research design in which both questionnaire and observation of traffic (traffic count) were used as instruments of data collection, the study used the Willingness to Accept (WTA) method to estimate the opportunity cost of traffic congestion trip-time delay as the value which motorist attached to the extra travel time spent in congestion at the intersection. The extra vehicle operating cost was estimated using data obtained from the traffic count, the prevailing fuel cost in Nigeria and mathematical models derived from multiple literatures reviewed in the study. It was found that the aggregate economic cost of traffic congestion trip-time delay and extra fuel cost to the economy of Imo state runs into billions of naira for trip-time delays experienced by motorists travelling in the major modes of cars, taxis, buses and trucks at intersection.
\end{abstract}

Keywords: Traffic-congestion, costs, opportunity-costs, Owerri-metropolis, Nigeria. 


\subsection{Introduction}

In the views of Caves (2004), Traffic congestion is a transport problem characterized by a condition of slower vehicle speeds leading to delays and longer trip times and vehicular queue on a motorway. It is mostly a common problem associated with inadequacy in the supply of transport capacity/infrastructure in terms of road networks, terminal space and facility witnessed frequently at intersections where capacity of the infrastructure cannot adequately cope with the demand for use of the transport infrastructure. Caves (2004) observe that traffic congestion on urban road networks has become increasingly problematic since the 1950s. He notes that when the traffic demand is great enough that the interaction between vehicles slows the speed of the traffic stream and the problem of congestion emanates.

Alberto (2004) notes that the fundamental cause of traffic congestion is the friction or mutual interference between vehicles in the traffic flow, particularly at road intersections. At higher levels of traffic, however, every additional vehicle interferes with the circulation of others, causing the phenomenon of congestion to appear. Thus Alberto (2004) and Thomson and Bull, (2001) view congestion as a situation where the introduction of an additional vehicle into a traffic flow increases the journey time of the others. According to Alberto (2004), as traffic increases, traffic speeds go down more and more sharply.

Thus, traffic congestion is seen as a transport problem which leads to overcrowding of road vehicle on a transport infrastructure, occurring when the demand for use of a road infrastructure or intersection nears the capacity of the travel infrastructure, transit time rise to a much higher level than that obtaining in conditions of low demand (Ortúzar and Willumsen, 1994). In line to the definition above, Alberto (2004) opine that a road is considered to be congested when, in more than half of its total length (including not necessarily continuous stretches), the average speed of the traffic flow was less than $40 \%$ of the speed in unrestricted conditions (Alberto, 2004). Chilean Draft Law on traffic congestion (2019) state that the term congestion could be defined as "the situation which occurs if the introduction of a vehicle into a traffic flow increases the travel times of the other vehicles by more than $x \%$ ". Chilean draft law on congestion presents an objective but somewhat arbitrary definition of congestion as the volume of traffic at which $d(q t) / d q=a t$, where $a$ equals, for example, 1.50. In other words, congestion would begin when the increase in the journey time of all the vehicles already present in the flow was equal to half of the travel time of an additional vehicle (Chilean draft law, 2019).

As demand for transport in terms of demand for use of road infrastructure, intersections, junctions and roundabouts approaches the capacity of a road and/or of the intersections along the road; extreme traffic congestion sets in. Road intersections, road junctions and roundabouts are known to be characterized as points of frequent traffic congestion. This is because as road vehicles approach road intersections and junctions, safety culture motivates the driver to decelerate and reduce speed in anticipation that other vehicles may be approaching the intersections from other connected routes. This reduction in speed and the demand for the use of the intersection by many vehicles from different roads linked by the intersection causes an excessive demand situation where the capacity of the intersections becomes unable to service the needs of all the road users at the same time, leading to clustering of vehicles at the intersections and a traffic congestion problem. Intersections thus increases the frequency of vehicles interfering/intercepting the flow of one another in a traffic flow with subsequent reductions in speeds and congestion as vehicles in the traffic interfere with each other. 
Alberto (2004) argues that traffic congestion happens as traffic volume in a modal split (ship traffic, vehicle traffic, air traffic, private cars, trucks, tricycles, etc) generates demand for space greater than the available road, lane, and/or street capacity. Thus, a point of saturation is reached where there is inadequacy in space and/or capacity of the road infrastructure to accommodate and serve all the vehicles at the same time. A queue of vehicles develops on the transport infrastructure waiting in a line to be passed through. The queue is marked by very slow movement of the vehicle on the waiting line and most time zero speed for a long period of time such that man hours and fuel is wasted without the vehicles on the queue making any head way.

Because of the flow of traffic from conflicting directions at intersections, traffic spends less time moving when it reaches an intersection than when it is flowing along an arc or straight line. Intersections as a results becomes easily prone to problems of congestion; they become congested first before the other straight sections of the road network causing bottlenecks and operational restrictions for the entire road network. The design of intersection therefore demand that consideration be made on its ability to adequately accommodate high volume traffic and allow relatively free traffic flow via it without getting easily congested.

Like many global cities, Nigerian cities over the years has grappled with the problem of traffic congestion induced by rapid increase in urban population and demand for inter and intra city travels. This is exactly the case with Owerri metropolis where serious problems of traffic congestions has over the years been experienced at major junctions and intersections such as the Control post, Wethedral road by Emmanuel College Intersection, Orlu-road by warehouse intersection, Port-Harcourt-road by House of Assembly junction, Government House roundabout by bank road, among others. The improvement in per capita income and revenue earnings of majority of city dwellers and families has also led to increase in private car ownership and use as well as increase in demand for use of public transport within the city. This has put and/or increased the pressure on the available transport infrastructures within the city whose supply over the years has not significantly increased relative to the demand for service via the infrastructures. There is therefore competition for access and use of city roads by motorist. This worsens the traffic congestion problem in most Nigerian cities. The city of Owerri in the South-Eastern part of the country is home to about 3.5million city inhabitants (projections based on 2007 census). The statistics of vehicle registration per annum in the City of Owerri from to 2012 and the flow traffic through the major roads in the city in peak hours is as shown below: 
Journal DOI: www.doi.org/10.46654/RJMP

Article DOI: www.doi.org/10.46654/RJMP.1509

Table1: Statistics of Vehicle Registration in Owerri from 2002 to 2012.

\begin{tabular}{|l|l|l|l|l|l|l|l|}
\hline Year & cars & buses & lorry & Pick up & truck & motorcycle & total \\
\hline 2001 & 901 & 559 & 19 & 253 & 62 & 14563 & 16357 \\
\hline 2002 & 12501 & 5604 & 156 & 863 & 134 & 12356 & 31614 \\
\hline 2003 & 17543 & 7640 & 4 & 165 & 5 & 14567 & 39924 \\
\hline 2004 & 1450 & 560 & 24 & 35 & 20 & 5227 & 7316 \\
\hline 2005 & 1245 & 430 & 36 & 40 & 3 & 6550 & 8304 \\
\hline 2006 & 2756 & 105 & 5 & 19 & 0 & 2504 & 5402 \\
\hline 2007 & 482 & 156 & 13 & 16 & 0 & 3110 & 3777 \\
\hline 2008 & 58 & 30 & 0 & 3 & 0 & 1256 & 1347 \\
\hline 2009 & 65 & 18 & 98 & 0 & 1 & 1023 & 1205 \\
\hline 2010 & 875 & 300 & 20 & 24 & 0 & 3560 & 4779 \\
\hline 2011 & 1023 & 205 & 47 & 10 & 0 & 3010 & 42950 \\
\hline 2012 & 2850 & 356 & 35 & 24 & 6 & 1456 & 4727 \\
\hline total & 41749 & 15963 & 470 & 1452 & 231 & 69182 & 1290447 \\
\hline
\end{tabular}

Source: Omenikolo et al. (2017)

Table 2. Vehicular Traffic Flow on Major Land Routes in Owerri Metropolis

\begin{tabular}{|l|l|l|l|l|}
\hline Route/Time & $\mathbf{8 a m}-\mathbf{1 0 a m}$ & $\mathbf{1 2 p m - 2 p m}$ & $\mathbf{4 p m}-\mathbf{- 6 p m}$ & Total \\
\hline Okigwe Road & 4568 & 2450 & 5465 & 12483 \\
\hline Douglas Road & 12345 & 4568 & 5320 & 22233 \\
\hline Wetheral Road & 5780 & 3560 & 4420 & 13760 \\
\hline Portharcourt & 3520 & 2761 & 5342 & 11623 \\
\hline Onitsha Road & 3450 & 3450 & 4427 & 11562 \\
\hline Total & 29898 & 16789 & 24974 & 71661 \\
\hline
\end{tabular}

Source: Omenikolo et al. (2017)

Given the trend of vehicle acquisition and use In Owerri metropolis over the years, the City continues to face risks of travel time delay associated with traffic congestion, particularly at major intersections such as Orlu road junction. The far low capacity of many of these intersections relative to high demand for service via them by motorists significantly contribute to the perennial problem of traffic congestion in Owerri metropolis. As a result, motorist, city dwellers and transport planners have always advocated for capacity planning measures as well as capacity management measures to address the problem. While governments over the years have continued to use capacity management measures by the use of traffic management policies and instruments to address the problem of traffic congestion at this intersection, the problem persists and has never been adequately addressed. Thus, there seems to be a serious need to adopt capacity planning measures which will aim at increasing capacity supply by improving the capacity of the intersection to handle higher traffic volume at any point in time and by constructing bridges and/or flyovers (interchanges) in order to provide permanent solution to the traffic congestion problems at the intersection. The same capacity planning measures may serve similar needs in other major intersections in Owerri metropolis that is marked by serious traffic congestion problem.

To do this, there is need that economic analysis be conducted to provide justification for such lump sum investment in transport infrastructure needed to eliminate the traffic congestions challenges within the city. It is expected that the investment and/or cost of constructing such transport infrastructures be justified by the economic savings it will make in the economy of 
the city dwellers and government at the end of day. This motivated the study to estimate some costs of traffic congestion trip time delay and the related extra fuel costs.

\subsection{Aim and Objectives of the Study.}

The main aim of the study is to estimate some costs of urban traffic congestion transportation problem at Orlu road junction in Owerri metropolis.

The specific objectives of the study are:

(i) To estimate the cost of traffic congestion trip-time delay at the orlu-road by warehouse intersection in Owerri Metropolis.

(ii) To measure the extra vehicle operating cost (VOC) as a result of traffic congestion travel time delay at Orlu road junction in Owerri.

\subsection{Research Questions}

(a) What is the cost of traffic congestion trip-time delay at Orlu junction in Owerri metropolis?

(b) What is the extra vehicle operating cost (VOC) related to traffic congestion trip-time delay at the intersection.

\subsection{Brief Review of Literature Review}

To most road users, the concept of traffic congestion entails motionless or slowly moving queues of vehicles on the highway, city road or urban street, occurring as result of a lane being blocked, accident on the road or ongoing construction and/or some other forms of obstruction hindering the free flow of traffic (Ian, 2003). According to Ian (2003), academics and transportation professionals involved in the study of transport and its practice, on the other hand, view congestion in terms of level of saturation of traffic flow on a road network, flow rates, road infrastructure capacities inadequacy, decline in vehicle speeds, and delay in travel via a road network. They thus view congestion as a phenomenon which occurs when the road capacity does not meet traffic demand at an adequate speed, and/or traffic controls are improperly used, leading to the cluster of vehicles on the road and/or intersection to the point of saturation during any time of the day and along any type of roadway. Ian (2003) suggests that congestion takes various forms, such as recurring or nonrecurring, and can be located across a network or at road intersections. Recurring congestion exists when the traffic volume on roadway exceeds its capacity at a particular location during a predictable and repeated time of day such as during rush hour to work and/or home after close of work. Nonrecurring congestion is caused by random or unpredictable events that temporarily increase, demand, or reduces capacity on a roadway. Such events include accidents, disabled vehicles, road construction, and inclement weather, etc (Ian, 2003).

Aftabuzzmman (2008) in examining the determinants of traffic congestion opines that the definitions of traffic congestion influence the determinants and measures of it. He explains that congestion can be defined in various ways depending on the perception of the definer. Aftabuzzmman (2008) and Downs (2004) however, notes that so far, there is no universally accepted definition of traffic congestion. He categorized the various definitions of traffic congestion into three different groups as follows: (i) demand capacity related, (ii) delaytravel/trip time related, and (iii) cost related (Aftabuzzmman, 2008). As it relates to demand capacity, traffic congestion is defined as a phenomenon which occurs when travel demand on a road and/or transport infrastructure exceeds the existing road infrastructure system capacity. The above definition corroborates that of Rosenbloom, (1978) who defined congestion as a 
condition in which the number of vehicles attempting to use a roadway at any time exceeds the capacity of the roadway to carry the load at generally acceptable service levels. Aftabuzzmman (2008) finally defines congestion it as it relates to cost, as traffic problem that leads to the incremental costs of road usage, resulting from interference among road users. We adopt the cost approach of definition of traffic congestion as this satisfy the scope the study which seeks to estimate some costs of traffic congestion in Owerri Metropolis.

A congestion index which is a dimensionless quantity greater than or equal to zero, denotes the level of congestion as defines the delay in the system. Thus the system delay may be expressed in tens of congestion index (eI) which is dimensionless (Taylor, 2003). A congestion index of one is an indication that the actual trip-time is twice the free-flow travel time (Taylor, 2003). The index is given the ratio of actual speed to free flow speed or the degree of saturation (Taylor, 2003).

Thompson and Bull (2001) argues that the major reason for the problem of traffic congestion in major cities is the preference for the use of private cars as against the use of public (bus) transport system. According to Thompson and Bull (2001), this has led the preponderance of private car users in many cities; this translates to higher demand for access to transport infrastructures while imbalance in infrastructure supply and demand in favour of the demand size leads to congestion. Since private cars generally have lower carrying capacity than public transport systems, it high usage in majority of cities induces traffic congestion at major intersections and roundabouts.

The state of the roads and driving habits are also identified to contribute to congestion in which case faulty and/or wrong design and poor maintenance culture of road infrastructure cause traffic congestion. This is a major cause of traffic congestion in most Nigerian cities marked with the preponderance of potholes and bad designs. In most Nigeria urban cities such as Owerri, there exist cases of failure to mark traffic lanes, cracks in major sections of the road, unexpected changes in the number of lanes, bus terminals situated precisely at locations where the road width is narrower, dilapidation of road and other shortcomings that obstruct the smooth flow of traffic. These constrain traffic flow and lead to problems of congestion.

In terms of road use behavior and habit of road users, there are drivers with incurable bad habit of lack of respect for other road users. Such drivers are known to frequently force their ways into intersections and blocking the passage of other motorists; leading to traffic congestion with the attendant problem of economic losses, trip time variability, emissions etc. The habit of parking cars by the sides of the major ways in most cities and urban centers in Nigeria and constitute a bad road use behavior that causes traffic congestion as it obstructs the free flow of traffic via the lanes.

Institutional inefficiency has also been established in many literatures to Causes traffic congestion. There exist institutions or government responsible for traffic management and for ensuring free flow of traffic in most cities in Nigeria. These institutions over time have failed to live up to their responsibilities as the levels of traffic congestion in most cities in Nigeria clearly provide evidence to the failure of the traffic management institutions. This is partly because of inappropriate actions by the corresponding authorities. The problem seems to have obviously overpowered the capability of the institutions to deal with it. So far, the reactions of the traffic management agencies have been ineffective over the years. The responsibility 
for urban transport planning and management is split up among a host of bodies, including various national ministries, state governments, municipalities, companies, the traffic police, etc.

Several theories form the theoretical basis for explaining the traffic congestion phenomenon. The queuing theory, traffic flow theory, the three phase traffic theory, among others, forms the theoretical framework that explains the occurrence and effects of traffic congestion. The queuing theory for example developed by Agner Krarupt Erlang in 1900s deals with the mathematical study of queues or waiting lines. It posits that when limited service facilities fail to satisfy all demands simultaneously, a bottleneck occurs that generates a queue or a waiting line on the facility. In the case of traffic flow through a road infrastructure or road intersection, when the capacity of the intersection or road infrastructure is limited such that it cannot satisfy all the demand for road use by the motorists simultaneously, a bottleneck occurs leading to the formation of waiting lines on the road and/or intersection. This form of waiting line is technically termed traffic congestion. It has its attendant problems as it increases trip time among other challenges. Queuing theory can thus be used as basis to analyze and explain the traffic congestion phenomenon as it plays important roles the capacity design of systems such as road infrastructures and intersections involving waiting lines as well as be useful in scheduling of services (Nwaoruh, 2009).

Traffic Flow theory studies individuals and vehicle drivers trip and/or movement of vehicles between two points cum the forms of interactions the vehicles and heir drivers make with one another when in traffic. It was originally developed in 1975 by an American psychologist Mihaly Csikszentmihalyi. In the opinion of Lieu (1999), traffic flow theory is a complex model for explanation of traffic congestion challenges because driver behavior most times cannot be predicted with a high degree of certainty or a one-hundred percent certainty. Traffic flow theory thus suggests that drivers tend to behave within a reasonably consistent range; such that traffic streams equally tend to have some reasonable consistency to be roughly represented using mathematical models. Traffic theory therefore represents traffic flow through a road infrastructure as a relationship between three main characteristics which include (i) Flow, (ii) Density and (iii) velocity (Laval; Toth, and Zhou, 2014).

The theory states that traffic behaves in a complex and nonlinear manner, depending on the interactions between large numbers of vehicles. It opines that the individual reactions of drivers, and vehicles do not strictly follow the laws of mechanics in their interactions but form clusters and shock waves influenced by vehicle density on the route.

According to Laval; Toth, and Zhou, (2014) in a free-flowing network, traffic flow theory refers of the relationship between to the traffic variables of speed, flow, and density or concentration. The relationship is aimed at ensuring uninterrupted flow of traffic on a road infrastructure. It states that traffic flow conditions are considered "free" when there are less than 12 vehicles per mile (traffic density) are on a road infrastructure (Laval; Toth, and Zhou, 2014). It is stable when it is between $12-30$ vehicles per mile on a lane. When the density exceeds 30 vehicles per mile, the density reaches maximum point referred to mass flow rate or flux classified as unstable traffic flow such that even a minor incident of disruption can lead to persistent traffic congestion problem and stop-and-go driving conditions. Knoop and Daamen (2017) notes that when traffic becomes unstable and reaches 67 vehicles per mile, a traffic breakdown condition occurs while jam density sets in extreme cases when traffic flows stops completely usually in the range of 185-250 vehicles per mile. 
These relationships help in planning, design, and operations of roadway facilities in urban and suburban centers.

Empirical studies carried out by Alia, et al (2013) on Estimation of Traffic Congestion CostA Case Study of a Major Arterial in Karachi among other things determined the cost of per minute trip-time delay in Karachi related to traffic congestion. The estimated VOT values are utilized to measure opportunity cost component of traffic congestion cost. The results indicate that Pak Rs. 1 million are lost daily due to traffic congestion, which is extrapolated for whole Karachi. The amount the study found is a composition of opportunity cost and fuel consumption costs caused due to excessive delays in congestion (Alia, et al, 2013).

In a similar but different study, Sougata (2017) carried out a study titled 'Traffic Congestion and Possible Solutions: A CASE STUDY OF ASANSOL'.

Considering the infrastructural gap in Asansol city and operational in efficiencies; the paper described the factors causing the congestion on the city road and after that present some recommended measures like rationalizing the design of road, implementation of the regulation for road users. The study found that the location of markets, schools, bus stops, businesses and service centers within the same area of the city causes the most significant congestion and delay problems in the city. It also found that during peak hours, an average total of 560 buses, 261 trucks, 1584 bikes, 649 wheelers. The suggested separating residential areas from business and industrial areas via proper urban/city planning as a way of solving the problem (Sougata, 2017).

Gavanas et al (2017) did a study on Assessment of the marginal social cost due to congestion using the speed flow function. Gavanas et al. (2017) identified that an integrated strategy was recently set out in Europe regarding the internalization of external costs from transport, which he regarded as the costs from the negative externalities to the society generated by the transport users. He identified the externalities as the impacts on the rest of transport users, such as delays due to congestion, accidents and scarcity of infrastructure, and the society, such as pollution, noise, energy dependency and spatial impacts, as well as to the global impact of greenhouse gas emissions on climate change. The objective of the study was to determine the marginal cost imposed by traffic congestion on the economy. The findings indicate a considerable difference in the marginal and total social costs due to congestion between the values that correspond to the average hourly speed during a typical workday and the 85 percentile hourly speed of a workday (Gavanas et al, 2017). This is due to the influence of traffic speed on the delays and the related costs (Gavanas et al, 2017). The study findings also support the finding of the study of DIW econ et al. (2014), that the European Union's average "Efficient Marginal Congestion Cost" for 2010 concerning cars along main urban roads in "near capacity" traffic conditions is equal to $0.487 € /$ vehicle kilometer.

The significance of the study is that it provides a measure of the real monetary cost of traffic congestion.

In Nigeria, Omenikolo, Uduma, Chinekeokwu, and Abara (2017) carried out a study on 'Assessment of air pollution generated by transport in Owerri, South East, and Nigeria'. The study identified that the rapid growth in motor vehicle activity in Owerri municipal and its environs contributes to high level of urban air pollution, among other adverse socioeconomic, environmental, health, and welfare impacts. Vehicular emissions are significant contributors 
to ambient air pollution, especially in urban areas. This paper reviews the status of vehicle emissions and their health impacts (Omenikolo, Uduma, Chinekeokwu, and Abara, 2017). The paper proffered preventive measures and remedial strategies for reducing the impacts of congestion induced excess gas emission from transport units on the health of urban dwellers.

Ukpata and Etika (2012) studied Traffic Congestion in Major Cities of Nigeria.

This study investigated traffic congestion in urban cities of Nigeria using Calabar city, CrossRiver state as case study. It adopted a survey approach, which was conducted during the Annual National Conference of the Nigerian Society of Engineers (NSE held between 5th and 9th December 2011 at the Calabar Tinapa Business and Leisure Resort. The results show that poor driving habits, poor road network, inadequate road capacity, and lack of parking facilities constitute the greatest causes of traffic congestion in Nigeria. Also, Lagos, Port Harcourt and Abuja were identified as cities most affected by traffic congestion (Ukpata and Etika, 2012).

The works of Ukpata and Etika (2012) identified the major causes of traffic congestion in Nigerian cities while also suggesting remedial measures for traffic congestion. Omenikolo, Uduma, Chinekeokwu, and Abara, (2017) obtained data on the trend of vehicles registered within Owerri spanning for a period of ten (10) years from Imo State Licensing office based upon which they analyzed congestion induced vehicular emission in Owerri metropolis. Currently, there is seeming lack of literature in the study of urban traffic congestion in Nigeria with priority in Owerri metropolis that seek to provide empirical evidences on the economic costs related to traffic congestion trip-time delay in major intersections. The bridging of this literature gap will provide basis for investment decision for road infrastructural capacity expansion as long-term solutions to traffic congestion challenges in Owerri. The current study therefore is cast to fill the existing literature gap as identified above.

\subsection{Materials and Methods}

\subsection{Research Design}

Research design is defined as the plan structure and strategy to the research investigation adopted in order to obtain answers to research questions and provide solutions to the research problems while achieving the objectives of the research. These include survey, Time series and/or historical, case studies and observational and experimental research designs.

The study thus employed a survey design method in which survey method was used in the conduct of this research. The survey design was employed to gather the empirical data using questionnaires administered to road users at the selected road intersection to gather than on the opportunity cost of avoiding the traffic congestion experience and the valued of time for each category of road users, using the willingness to pay method (WTP). The field observation approach was used also in which the Orlu-road-warehouse intersection was used as case studies for other intersections in Owerri and traffic count was carried out for each intersection travel mode type. The traffic conditions of flow, speed, density, trip time and associated delay, at peak and off peak traffic periods at the intersection was observed and recorded for purposes of being used in data analysis to achieve the objectives of the study. 


\subsection{Sources of Data and Methods of Data Collection}

The study used survey research design approach in which data was obtained from primary sources using field observation/survey methods and questionnaire as survey instruments. The filed survey involved traffic count during periods of traffic congestion at the intersection as well as administration of questionnaire. The traffic condition data was collected into three time phases, morning afternoon and evening, with time intervals between 7.30am to 9.30am, $12.00 \mathrm{pm}$ to $2.00 \mathrm{pm}$ and $4.00 \mathrm{pm}$ to $5.30 \mathrm{pm}$ respectively. The morning and evening hours were considered so as to capture peak hours while the afternoon hours were considered to observe the conditions of traffic during off peak hours. The data at each intersection was collected for two different days that are two weeks apart, in order to counter the effect of variations. Traffic volume data was characterized into different travel modes covering private cars, buses, trucks etc while the trip-time delay was determined from respondents.

The survey employed questionnaires to determine the value that commuters of various modes attach to the time spent in traffic congestion using the willingness to accept (WTA) method viewed as the congestion opportunity cost for each category of travelers. The idea is to gather data to estimate the value of time (VOT) of individuals travelling in different modes (cars, Trucks, Buses) using an indirect technique based on estimating mode specific utility equations that includes trip-time and travel cost parameters as part of a multinomial logit model form. The estimated values of time (VOT) will be utilized as the opportunity cost component of traffic congestion. Fuel efficiency and fuel consumption data for different types of modes (cars, trucks, buses) prevailing in the roads will be gathered using survey method to estimate vehicle extra operating cost component of traffic congestion. The survey instrument was administered to randomly selected 30 of travelers and road users in each travel mode of bus, private car, truck and taxi.

\subsection{Methods of Data Analysis}

The data collected was analyzed using SPSS statistical software for generating descriptive statistics. The data gathered representing the traffic condition on the selected road intersection on the opportunity cost of traffic congestion trip-time delay was analyzed using the methods discussed below:

Formulae derived by Ali et al (2014) and Gananas (2016) were adopted and used to determine the economic cost of congestion trip-time delay and excess fuel usage by vehicles in traffic congestion.

The economic cost of trip time delay representing the opportunity cost component and value of time spent in traffic congestion can be evaluated by equation (1) below:

$$
O C=\sum_{M=1}^{M}(V O T m)(D E L A Y m)(V m)(V O C C m
$$

Where, $O C=$ Economic/Opportunity cost of traffic congestion, $V O T_{m}=$ Value of time spent in traffic congestion for specific mode $\mathrm{m}, D E L A Y_{m}=$ trip-time delay, in time units observed for mode $\mathrm{m}$ (estimated at some reference speed), $V_{m}=$ number of vehicles of type $\mathrm{m}$ per day, $V O C C_{m}=$ Average vehicle occupancy per specific mode $m$.

Similar, the cost of excess fuel spent in traffic congestion as a component of the vehicle operating cost was estimated by using the equation (2) below: 
Journal DOI: www.doi.org/10.46654/RJMP

$V O C=L * \sum_{m=1}^{m}(F C m * D E L A Y m * V m)$

Where, VOC $=$ Vehicle operating cost, $\mathrm{FC}_{\mathrm{m}}=$ fuel cost in naira $(\mathrm{N})$ per hour for specific mode $\mathrm{m}, \mathrm{V}_{\mathrm{m}}$ and DELAY $\mathrm{m}$ are as explained in ---(1), $\mathrm{L}=$ Length of stretch in $\mathrm{Km}$.

$\mathrm{FC}_{\mathrm{m}}$ is calculated using equation (3) as shown below:

$F C m=\sum_{f t=1}^{2} \quad\left(F c q_{m}^{f t} * F p^{f t} * \beta^{f t}\right)$

Where, $F c q_{m}^{f t}=$ fuel consumption quantity in liters per $\mathrm{km}$ or $\mathrm{kg} / \mathrm{km}$ of specific mode $\mathrm{m}, F^{f t}=$ fuel price of specific fuel types $f t=1$ such as gasoline and diesel respectively in naira (N) per liter, $\beta^{t t}=$ proportion of specific mode type $m$ using a particular fuel type for traveling on that road stretch.

Using the methods discussed above the data collected for the study was analyzed and findings discussed in subsequent paragraphs.

\subsection{Presentation of data, Results and discussion \\ 4.1 Data Presentation}

Table 4.1 Traffic held up at the intersection

\begin{tabular}{|c|c|c|c|c|c|c|}
\hline Mode & Date & $\begin{array}{l}\text { 7.30AM- } \\
9.30 \mathrm{AM}\end{array}$ & $12.0 \mathrm{PM}-2.0 \mathrm{PM}$ & $\begin{array}{l}4.0 \mathrm{pm}- \\
5.30 \mathrm{pm}\end{array}$ & $\begin{array}{l}\text { Mode } \\
\text { Total }\end{array}$ & $\begin{array}{l}\text { Daily } \\
\text { Average }\end{array}$ \\
\hline \multirow[t]{2}{*}{ Cars } & Monday: & 3406 & 2245 & 4104 & \multirow[t]{2}{*}{19583} & \multirow[t]{2}{*}{9792} \\
\hline & Tuesday: & 3466 & 2543 & 3819 & & \\
\hline \multirow[t]{2}{*}{ Trucks } & Monday: & 230 & 788 & 192 & \multirow[t]{2}{*}{1709} & \multirow[t]{2}{*}{855} \\
\hline & Tuesday: & 212 & 70 & 217 & & \\
\hline \multirow[t]{2}{*}{ Taxi } & Monday: & 4813 & 2796 & 3417 & \multirow[t]{2}{*}{20224} & \multirow[t]{2}{*}{10112} \\
\hline & Tuesday: & 4396 & 2045 & 2757 & & \\
\hline \multirow[t]{2}{*}{ Bus } & Monday: & 879 & 382 & 746 & \multirow[t]{2}{*}{3434} & \multirow[t]{2}{*}{1717} \\
\hline & Tuesday: & 482 & 321 & 624 & & \\
\hline \multirow[t]{2}{*}{ TOTAL } & & 20884 & 11190 & 15,878 & \multirow[t]{2}{*}{44950} & \multirow[t]{2}{*}{22475} \\
\hline & $\begin{array}{l}\text { Daily } \\
\text { Average }\end{array}$ & 10,442 & 5595 & 7939 & & \\
\hline
\end{tabular}

SOURCE: Filed survey

The table is a presentation of the data obtained from traffic survey carried out at the warehouse by Orlu road intersection to count and determined the number of road vehicles of various types (modes) stuck in traffic congestion at various periods of the day. The survey and traffic counting was carried out for two different days from which average was determined in order to avoid reduce error that may arise from using a single day's traffic congestion data. The survey indicates as shown on the table that in the two days the survey was carried; between 7.30am and 9.30am in the morning, a total of 20,884 vehicles comprising of private cars, trucks, taxis, and buses were stuck in traffic congestions at the warehouse intersection. Between 12.00noon and $2.0 \mathrm{pm}, 11,190$ vehicles of all types were stuck in traffic at the intersection in the two days of the survey. Between $4.0 \mathrm{pm}$ and $5.30 \mathrm{pm}$, only a total 15,878 were observed to be trapped in traffic congestion at the intersection. This indicates daily averages of 10,442, 5595, and 7939 vehicles comprising of cars, trucks, taxis and buses in traffic congestion between $7.3 \mathrm{am}-9.30 \mathrm{am} ; 12.0 \mathrm{noon}-2.00 \mathrm{pm}$ and $4.0 \mathrm{pm}-$ $5.30 \mathrm{pm}$ respectively. 
Journal DOI: www.doi.org/10.46654/RJMP

Vol. 1, Issue 5 (May, 2021) |www.ijaar.org

Article DOI: www.doi.org/10.46654/R.JMP.1509

The average daily number of vehicles of different modes (types) involved in traffic congestion at the warehouse-Orlu road intersection as shown on the tables is 9792 private cars, 855 trucks, 10112 Taxis, and 1717 buses respectively. The Table also indicates an aggregate daily average 22,475 vehicles of all kinds stuck in traffic congestion at the Orlu $\mathrm{road} / \mathrm{warehouse}$ intersection.

Table4.2: Value of congestion trip-time delay at Intersections By Modes

\begin{tabular}{|c|c|c|c|c|c|c|c|c|}
\hline \multirow{2}{*}{$\begin{array}{l}\text { S/N of } \\
\text { Respondents }\end{array}$} & \multirow{2}{*}{$\begin{array}{l}\text { Cars } \\
\text { Delay } \\
\text { (Minute } \\
\text { s) }\end{array}$} & \multirow{2}{*}{$\begin{array}{l}\text { Cars } \\
\text { Time } \\
\text { Value } \\
\text { N }\end{array}$} & \multicolumn{2}{|c|}{ Truck } & \multicolumn{2}{|r|}{ Taxi } & \multicolumn{2}{|r|}{ Buses } \\
\hline & & & $\begin{array}{l}\text { Delay } \\
\text { (minutes) }\end{array}$ & $\begin{array}{l}\text { Time } \\
\text { Value } \\
\mathrm{N}\end{array}$ & $\begin{array}{l}\text { Delay } \\
\text { (minute } \\
\text { s) }\end{array}$ & $\begin{array}{l}\text { Value } \\
\text { Time } \\
\text { N }\end{array}$ & $\begin{array}{l}\text { Delay } \\
\text { (minute } \\
\text { s) }\end{array}$ & $\begin{array}{l}\text { Time } \\
\text { Value } \\
\mathrm{N}\end{array}$ \\
\hline 1 & 35 & 4000 & 50 & 8000 & 30 & 4000 & 45 & 7000 \\
\hline 2 & 60 & 20000 & 35 & 10000 & 30 & 5000 & 40 & 7500 \\
\hline 3 & 30 & 8000 & 60 & 15000 & 35 & 3000 & 40 & 6000 \\
\hline 4 & 20 & 5000 & 30 & 12000 & 20 & 6000 & 60 & 10000 \\
\hline 5 & 25 & 10000 & 25 & 20000 & 25 & 6000 & 60 & 15000 \\
\hline 6 & 45 & 10000 & 45 & 15000 & 15 & 6000 & 15 & 2000 \\
\hline 7 & 25 & 40000 & 50 & 13000 & 15 & 7000 & 35 & 6000 \\
\hline 8 & 40 & 12000 & 20 & 7000 & 50 & 6000 & 20 & 7000 \\
\hline 9 & 30 & 10000 & 15 & 5000 & 50 & 5000 & 25 & 4500 \\
\hline 10 & 15 & 3000 & 60 & 20000 & 40 & 10000 & 60 & 8000 \\
\hline 11 & 15 & 6000 & 55 & 15000 & 45 & 4500 & 55 & 6000 \\
\hline 12 & 20 & 8000 & 50 & 12000 & 30 & 5000 & 35 & 3000 \\
\hline 13 & 40 & 50000 & 40 & 10000 & 25 & 4000 & 30 & 4000 \\
\hline 14 & 40 & 20000 & 30 & 10000 & 35 & 5000 & 15 & 6000 \\
\hline 15 & 30 & 35000 & 25 & 8000 & 30 & 6000 & 30 & 4500 \\
\hline 16 & 25 & 15000 & 30 & 10000 & 35 & 7000 & 20 & 3000 \\
\hline 17 & 30 & 50000 & 30 & 8000 & 25 & 4000 & 25 & 5000 \\
\hline 18 & 20 & 20000 & 18 & 6000 & 40 & 5000 & 20 & 3000 \\
\hline 19 & 30 & 35000 & 22 & 8500 & 25 & 4000 & 20 & 3000 \\
\hline 20 & 12 & 15000 & 28 & 10000 & 33 & 4500 & 15 & 5000 \\
\hline 21 & 30 & 10000 & 40 & 12000 & 22 & 3000 & 25 & 4000 \\
\hline 22 & 15 & 3000 & 60 & 15000 & 16 & 2000 & 27 & 4000 \\
\hline 23 & 40 & 20000 & 50 & 20000 & 20 & 3000 & 15 & 2000 \\
\hline 24 & 30 & 35000 & 25 & 5000 & 35 & 3500 & 35 & 6000 \\
\hline 25 & 20 & 5000 & 15 & 5000 & 45 & 4500 & 20 & 7000 \\
\hline 26 & 25 & 10000 & 35 & 15000 & 30 & 5000 & 25 & 5000 \\
\hline 27 & 45 & 10000 & 30 & 8000 & 25 & 4000 & 20 & 3000 \\
\hline 28 & 25 & 4000 & 40 & 10000 & 15 & 3000 & 20 & 3500 \\
\hline 29 & 30 & 20000 & 20 & 15000 & 50 & 5000 & 40 & 6000 \\
\hline 30 & 15 & 8000 & 60 & 25000 & 40 & 5000 & 60 & 10500 \\
\hline Aggregate & 862 & $\begin{array}{l}501,00 \\
0\end{array}$ & 1093 & $\begin{array}{l}352,50 \\
0\end{array}$ & 931 & 145000 & 952 & 83223 \\
\hline Average & 28.733 & 16700 & 36.433 & $\begin{array}{l}11750 . \\
0\end{array}$ & 31.033 & 4833.33 & 31.733 & 2774.11 \\
\hline
\end{tabular}

Source: Field Survey 
The table indicates the value that commuters of various modes attach to traffic congestion trip time delay based on the willingness to pay (WTP) method viewed as the opportunity cost of avoiding the traffic congestion for each mode of travel (car, truck, taxi, bus). It equally indicates the traffic congestion trip-time delay experienced by each travel mode sampled at the intersection. The data is to be employed to estimate the value of time (VOT) of individuals travelling in various modes using an indirect method.

The tables indicates that aggregates of 862 minutes, 1092minutes, 931 minutes and 952 minutes of trip-time delay was experienced by road users in the various travel modes of car, truck, taxi and bus respectively. This represent the aggregate amount of delay measured in units of time (minutes) that travelers using the various road modes experienced at the intersections over the period of the survey. These gave respective averages of 28.73 minutes, 36.43minutes, 31.033minutes and 31.73minutes of traffic congestion trip time delay at the intersections for every car, truck, taxi and bus involved.

The table further indicates that for experiencing time delay of the average magnitudes as afore stated, travelers by the various road modes of private car, trucks, taxis and buses based on the WTP method and individual specific values to time placed aggregates of 501,000 naira, 352,500naira, 145000naira, and 83223naira respectively as the economic value of the trip-time delays occasioned by traffic congestion at the intersections. These represent the opportunity costs of staying away from the traffic congestion. On the average, the values of the time (delay) spent in traffic congestion per individual traveler using the various road modes is 16,700naira for car mode, 11750naira for truck mode, 4833.33naira for taxi and 27774.11naira for buses; for average delays of 28.73minutes, 36.43minutes, 31.03minutes and 31.73 minutes respectively.

Table4.3: Distribution of Respondents and Characteristics of the Sampled Population that Filled and Returned the Questionnaire

\begin{tabular}{|c|c|c|c|c|c|c|}
\hline \multicolumn{2}{|l|}{ Transport Mode } & truck mode & $\begin{array}{l}\text { Private Cars } \\
\text { Mode }\end{array}$ & Taxi & Bus & Total \\
\hline \multicolumn{2}{|c|}{$\begin{array}{l}\text { Number of Respondents per } \\
\text { mode }\end{array}$} & 30 & 30 & 30 & 30 & 120 \\
\hline \multicolumn{2}{|c|}{$\begin{array}{l}\text { Average vehicle Occupancy } \\
\text { per mode (Persons) }\end{array}$} & 1.8 & 2.5 & 6 & 16 & 24.3 \\
\hline \multicolumn{2}{|c|}{$\begin{array}{l}\text { Pump/Fuel prices of specific } \\
\text { fuel types (PMS, AGO) }\end{array}$} & $\begin{array}{l}\text { N217 per } \\
\text { liter }\end{array}$ & $\begin{array}{l}\text { N145 per } \\
\text { Liter }\end{array}$ & $\begin{array}{l}\text { N145 per } \\
\text { Liter }\end{array}$ & N217 per liter & - \\
\hline \multirow{2}{*}{\multicolumn{2}{|c|}{$\begin{array}{l}\text { Fuel Consumption Quality } \\
(\mathrm{Km} / \text { Liter }) \&(\text { liters } / \mathrm{km})\end{array}$}} & $12.3 \mathrm{~km} /$ liter & $4 \mathrm{~km} / \mathrm{liter}$ & $10.8 \mathrm{~km} /$ liter & $7 \mathrm{~km} / \mathrm{liter}$ & \multirow[t]{2}{*}{-} \\
\hline & & $\begin{array}{l}\text { 0.0813liters/ } \\
\mathrm{km}\end{array}$ & 0.25 liters $/ \mathrm{km}$ & $\begin{array}{l}\text { 0.0925liters } / \mathrm{k} \\
\mathrm{m}\end{array}$ & $\begin{array}{l}\text { 0.1429liters } / \mathrm{k} \\
\mathrm{m}\end{array}$ & \\
\hline \multirow{2}{*}{$\begin{array}{lr}\text { Number } & \text { of } \\
\text { vehicles } & \text { using } \\
\text { specific } & \text { fuel } \\
\text { type } & \text { in } \\
\text { congestion } & \end{array}$} & Warehouse & 855 & 9792 & 10112 & 1717 & \\
\hline & $\begin{array}{l}\text { Emmanuel } \\
\text { college }\end{array}$ & 653 & 4215 & 5093 & 1752 & \\
\hline
\end{tabular}

Source: Energy commission of Nigeria, Abuja (2019)

The table provides the distribution of the number of road users sampled in generating data for the value of time and delay occasioned by traffic congestion at both intersections. It equally 
provides the data obtained from the survey on the average vehicle occupancy per mode. The average vehicle occupancy is a measure of the average number of persons occupying a road vehicle at each point in time and represents a measure of the carrying capacity of the vehicle at that point in time. In this study, it was determined by ascertaining the aggregate number of persons in each vehicle counted in the traffic at each intersection and determining the average for the respective modes. It indicates that the average vehicle occupancy for the different vehicles types (modes) is 1.8, 2.5, 6, and 16 for road trucks, private cars, taxis and busses respectively. Also the table shows the prices per liter of the different fuel types used by the modes. It indicates 145 naira per liter of premium motor spirit (PMS) as fuel type for car and taxi modes and 217 naira per liter for Automotive Gas Oil (AGO)/diesel as fuel type for trucks and buses. It equally indicates that the fuel consumption quantities for the modes are 0.0813 liters $/ \mathrm{km}, 0.25$ liters $/ \mathrm{km}, 0.0925$ liters $/ \mathrm{km}$ and 0.1429 liters $/ \mathrm{km}$ for truck, car, taxi and bus modes.

\section{2: Results and discussion}

Table 4.4: Opportunity cost/ economic cost of traffic congestion trip-time delay at warehouse-Orlu road intersection in Owerri metropolis

\begin{tabular}{|l|l|l|l|l|l|}
\hline Mode & VOT $_{\mathrm{m}}(\mathrm{N})$ & Delay & $\mathrm{V}_{\mathrm{m}}$ & $\mathrm{VOCC}_{\mathrm{m}}$ & OC $(\mathrm{N})$ \\
\hline Car & 16700 & 28.733 & 9792 & 1.8 & $8,457,487,292.16$ \\
\hline Truck & 11750. & 36.4333 & 855 & 2.5 & $915,045,100.31$ \\
\hline Taxi & 4833.333 & 31.0333 & 10112 & 6 & $9,100,452,530.78$ \\
\hline Bus & 2774.1106 & 31.7333 & 1717 & 16 & $2,418,406,420.18$ \\
\hline Aggregate & & & & & $20,891,391,343.43$ \\
\hline
\end{tabular}

Source: Authors calculation

The economic cost of trip-time delay representing the opportunity cost component was evaluated by equation (1) below:

$$
O C=\sum_{M=1}^{M}(V O T m)(D E L A Y m)(V m)(V O C C m)
$$

Thus the SPSS statistical software was used to determine the economic cost of traffic congestion trip-time delay at warehouse by Orlu road intersection in Owerri Metropolis. It shows that the economic cost of traffic congestion trip time delay experienced by the travelers on using private car mode is $\mathrm{N} 8,457,487,292.16$ ) for an average of 29 minutes trip time delay experienced by 9792 cars per day.

The economic cost of traffic congestion trip-time delay imposed by the truck mode at the intersection amounts to $\mathrm{N} 915,045,100.31$, for an average of 36 minutes time delay experienced by 855 road trucks per day.

The economic cost imposed on the economy by traffic congestion delay experienced by 10112 taxis is $\$ 9,100,452,530.78$ for an average of 31 minutes delay in traffic congestion at warehouse intersection. Similarly, for an average of 32 minutes time delay in traffic at the same intersection by 1717 passenger buses imposed an economic cost of ix thousand, four hundred and twenty naira eighteen kobo $\mathrm{N} 2,418,406,420.18$.

This indicates an aggregate economic cost of N20,891,391,343.30 . 
Thus $O C=\sum_{M=1}^{M}($ VOTm $)(D E L A Y m)(V m)($ VOCCm $)=\underline{N 20,891,391,343.43}$, for trip-time delay of between 28 minutes and 37 minutes experienced by an aggregate of 22,476 vehicles inclusive of cars, trucks, taxis and buses per one day. This translates to a cumulative economic loss of $\mathrm{N163}, 341,605.50$ per minute of trip time delay in traffic congestion for a traffic size of 22,476 vehicles inclusive of all modes at the intersection. By implication, the economic justification for the construction of overhead bridges and flyovers and improvement of transport infrastructure supply at the warehouse intersection to solve the problem of urban traffic congestion and travel time delay experienced by road travelers at that intersection is established. The result further indicates that the greatest economic loss is imposed by trip time delay experiences of travelers using the taxi mode; this is followed by the car mode, the bus mode and lastly the truck mode. The economic cost of traffic congestion time delay imposed by all the modes can thus be presented by the use of the pie chart shown below:

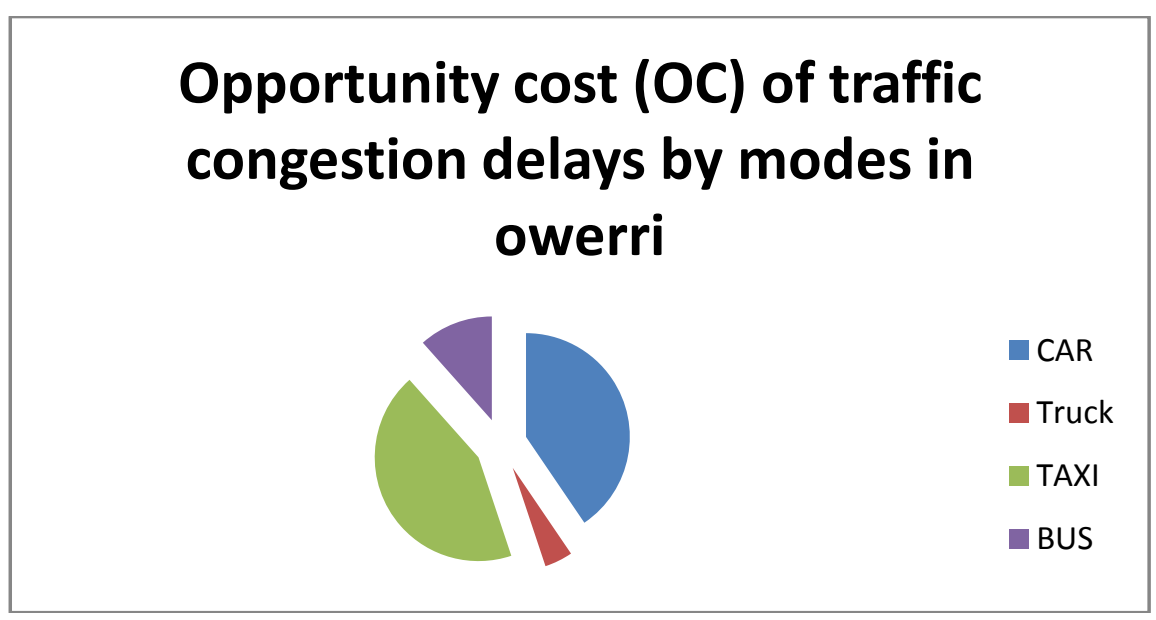

Source: Author's calculation

Table4.5: Cost of extra fuel consumption $\left(\mathrm{FC}_{\mathrm{m}}\right)$ in naira per $\mathrm{km}$ per mode delayed in traffic congestion at the Orlu-road-warehouse intersection.

\begin{tabular}{|l|l|l|l|l|}
\hline Mode/parameter(s) & $\begin{array}{l}\mathrm{FC}_{\mathrm{q}}^{\mathrm{ft}} \\
(\text { Liters/km) }\end{array}$ & $\mathrm{F}_{\mathrm{p}}^{\mathrm{ft}}-(\mathrm{N})$ & $\beta^{\mathrm{ft}}$ & $\mathrm{FC}_{\mathrm{m}}(\mathrm{N})$ \\
\hline Car & 0.25 & 145 & 9792 & $354,960.00$ \\
\hline Truck & 0.0813 & 217 & 855 & $15,084.00$ \\
\hline Taxi & 0.0925 & 145 & 10112 & $135,627.20$ \\
\hline Bus & 0.1429 & 217 & 1717 & $53,242.97$ \\
\hline Aggregate FC for all modes & & & & $\mathrm{N} 558,914.17$ \\
\hline
\end{tabular}

Source: Authors Calculation

Using the SPSS statistical software and equation--- (3)

$F C m=\sum_{f t=1}^{2} \quad\left(F c q_{m}{ }^{f t} * F p^{f t} * \beta^{f t}\right)$ as explained previously, the fuel cost $\left(\mathrm{FC}_{\mathrm{m}}\right)$ per kilometer by each mode in congestion was determined in order that the extra cost of operating the vehicle as a result of trip time delay in traffic congestion may be determined. The result indicates that the fuel consumption cost of navigating the car mode per kilometer is 
$\mathrm{N} 354,960.00$ for a traffic size of 9792 cars at 0.25 liters of fuel per kilometer purchased at the official rate of 145 naira per liter.

For truck mode with traffic size of 855 trapped and congestion and fuel consumption per kilometer of 0.0813liters at 217 naira official price, the fuel consumption per kilometer for the fleet size is 15, 084.00 naira. The respective fuel consumption cost per kilometer of taxi

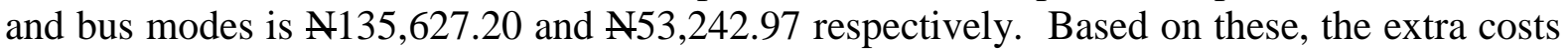
of operating the vehicles in each mode $\left(\mathrm{VOC}_{\mathrm{m}}\right)$ over the period of traffic congestion trip-time delay at the Orlu-road-warehouse intersection was determined as shown below:

Table4.6: Extra vehicle operating cost (VOC) as a result of traffic congestion trip-time delay by modes at the warehouse intersection.

\begin{tabular}{|l|l|l|l|l|l|}
\hline Mode/parameter(s) & $\mathrm{L}(\mathrm{km})$ & $\mathrm{FC}_{\mathrm{m}}(\mathrm{N})$ & $\begin{array}{l}\text { Delay } \\
(\text { minutes })\end{array}$ & $\mathrm{V}_{\mathrm{m}}$ & $\mathrm{VOC}_{\mathrm{m}}(\mathrm{N})$ \\
\hline Car & 0.75 & $354,960.00$ & 28.733 & 9792 & $74,901,938,353.92$ \\
\hline Truck & 0.75 & $15,084.00$ & 36.4333 & 855 & $352,405,284.08$ \\
\hline Taxi & 0.75 & $135,627.20$ & 31.0333 & 10112 & $31,920,749,498.40$ \\
\hline Bus & 0.75 & $53,242.97$ & 31.7333 & 1717 & $2,175,750,386.41$ \\
\hline Aggregate VOC & & & & & $109,350,843,522.81$ \\
\hline
\end{tabular}

Source: Authors Calculation

The extra vehicle operating cost $\left(\mathrm{VOC}_{\mathrm{m}}\right)$ as a result of traffic congestion trip time delay by modes at the warehouse intersection was determined using -(2) as shown below:

$\mathrm{VOCm}=L * \sum_{m=1}^{m}(F C m * D E L A Y m * V m)$

Thus, using the SPSS statistical software, the extra vehicle operating cost as a result of congestion time delay at the intersection per specific mode is shown in the table above. The table indicates that congestion at the warehouse intersection imposed extra vehicle operating cost $\left(\mathrm{VOC}_{\mathrm{m}}\right)$ of 74,901,938,353.92 naira for the private car mode of traffic size of 9792 cars per day spread over the 750 meter () $.75 \mathrm{~km}$ ) road stretch between warehouse intersection and control post in Owerri following an average trip-time delay of 28.733minutes. Also the $\mathrm{VOC}_{\mathrm{m}}$ for the truck mode of traffic size 855 on the same length of road is for 36.433 minutes traffic congestion trip-time delay is $352,405,284.08$ naira. The extra $\mathrm{VOC}_{\mathrm{m}}$ for taxi and bus modes on the same road stretch with respective average delays of 31.033 minutes and 32.00 minutes is $31,920,749,498.40$ naira and 2,175,750,386.41 naira respectively.

This translates to extra vehicle operating cost per minute traffic congestion trip-time delay at the intersection of $\mathrm{N} 2,606,826,240.00, \mathrm{~N} 9,672,615.00, \mathrm{~N} 1,028,596,684.80, \mathrm{~N} 68,563,634.62$ for car, truck, taxi and bus modes respectively with respective traffic sizes of up to 9792 cars, 855 trucks, 10112 taxis and 1717 buses per day. The aggregate extra vehicle operating cost at the intersection occasioned by traffic congestion trip-time delay involving all the modes identified above and given the traffic sizes and fuel consumption statistics as afore discussed is $\mathrm{N} 109,350,843,522.81$.

\subsection{Conclusion}

The aggregate economic cost of traffic congestion trip-time delay and extra fuel cost to the economy of Imo state runs into billions of naira for every unit trip-time delay experienced by 
motorists at intersection. When totaled, the cost of traffic congestion induced extra fuel

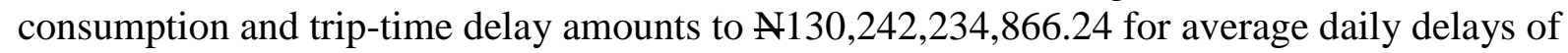
between 28 minutes and 37 minutes in traffic congestion at the intersection. There is therefore need for:

(1) Investment in overhead bridges, flyovers and other road infrastructures that will solve the perennial traffic congestion challenges at the intersection. This is because, the cost of such investment is justified by the enormous economic waste occasioned by traffic congestion trip-time delay and increases in vehicle operating costs along the corridor.

(2) Employment of serious traffic management measures as temporary strategy for control of traffic congestion at the intersection to reduce the associated economic cost. 


\section{References}

Aftabuzzaman M.D. (2008) Measuring Traffic Congestion- A critical Review, 30th Australia Transport Forum. Available at: (http://atfr.info/papers/2008-aftabuzzman.pdf. Retrieved on 18/10/2019.

Alia Mir S., Abbas Muhammad, Syed M.N., Syed F.B. (2014) Estimation of traffic congestion cost- A case study of major arterial in Karachi. Procedia Engineering 77(2014) 3-44.

Alberto B. (2004) Traffic congestion the Problem and how to deal with it. Available at: http://www.researchgate.net/publications. Retrieved 23/11/2019.

Downs, A. (2004) Still stuck in traffic: coping with peak-hour traffic congestion, Washington, D.C.: The Brookings Institution.

Gavanas N., Anastasios T., Magda P.L. (2017) Assessment of the marginal cost due to congestion using the speed flow function. Transportation research procedia vol. 24(2017) $250-258$.

Ian W. ((2013) The cost of congestion reappraised, Report 489, New Zealand Transport Agency. Available at: http://www. Nzta.govt.nz/resources/research/report/489. Retrieved 23/11/2019.

Knoop V. L. and W. Daamen (2017). Automatic fitting procedure for the fundamental diagram. Transportmetrica B: Transport Dynamics. 5 (2): 133-148. doi: $10.1080 / 21680566.2016 .1256239$.

Laval, Jorge A., Toth C.S., Zhou, Y. (2014-12-01) A parsimonious model for the formation of oscillations in car-following models. Transportation Research Part B: sMethodological. 70: 228-238. doi:10.1016/j.trb.2014.09.004. ISSN 0191-2615.

Nworuh G.E. (2009) quantitative techniques in transport. Unpublished lecture material at the Department of Transport management Technology, Federal University of Technology, Owerri.

Omenikolo A. I., Uduma C. I., Chinekeokwu T. and Abara J. C. (2017) Assessment of air pollution generated by transport in Owerri, South East, Nigeria. Merit Research Journal of Environmental Science and Toxicology (ISSN: 2350-2266) Vol. 5(1) pp. 009-017.

Ortuzar, J.D., Willumsen N. (1994), Modelos de demanda de transporte, Santiago, Chile, Department of Transport Engineering, Catholic University of Chile. Available at: http://www.researchgate.net/publications. Retrieved 23/11/2019.

Rosenbloom, S. (1978) Peak-period traffic congestion: a state-of-art analysis and evaluation of effective solution, Transportation, 7(2), 167-191.

Sougata M. (2017) Traffic Congestion and Possible Solutions A CASE STUDY OF ASANSOL. Journal of Research in Humanities and Social Science Volume 5 (9) pp.: $42-46$ 
Taylor, Brian D. (2002), Rethinking Traffic Congestion, Access, No. 21, Berkeley, University of California Transportation Center (http:// www.uctc.net/access/access.asp). Retrieved 23/11/2019.

Ukpata J. and Etika A. (2012) Traffic Congestion in Major Cities of Nigeria. International Journal of Engineering and Technology Volume 2 (8) 1433 - 1438. 